\title{
Gill filament permeabilization: A novel approach to assess mitochondrial function in sheepshead minnows (Cyprinodon variegatus) following anthraquinone exposure
} DOI:

10.1016/j.cbpc.2019.108699

\section{Document Version \\ Accepted author manuscript}

Link to publication record in Manchester Research Explorer

Citation for published version (APA):

Reynolds Kirby, A., Galli, G., Crossley, J., Sweet , L. E., Crossley II, D. A., \& Roberts, A. P. (2019). Gill filament permeabilization: A novel approach to assess mitochondrial function in sheepshead minnows (Cyprinodon variegatus) following anthraquinone exposure. Comparative Biochemistry and Physiology. Part C: Comparative Pharmacology. https://doi.org/10.1016/j.cbpc.2019.108699

\section{Published in:}

Comparative Biochemistry and Physiology. Part C: Comparative Pharmacology

\section{Citing this paper}

Please note that where the full-text provided on Manchester Research Explorer is the Author Accepted Manuscript or Proof version this may differ from the final Published version. If citing, it is advised that you check and use the publisher's definitive version.

\section{General rights}

Copyright and moral rights for the publications made accessible in the Research Explorer are retained by the authors and/or other copyright owners and it is a condition of accessing publications that users recognise and abide by the legal requirements associated with these rights.

\section{Takedown policy}

If you believe that this document breaches copyright please refer to the University of Manchester's Takedown Procedures [http://man.ac.uk/04Y6Bo] or contact uml.scholarlycommunications@manchester.ac.uk providing relevant details, so we can investigate your claim.

\section{OPEN ACCESS}




\section{Comparative Biochemistry and Physiology, Part C}

\section{Gill Filament Permeabilization: A Novel Approach to Assess Mitochondrial Function in Sheepshead Minnows (Cyprinodon variegatus) following Anthraquinone Exposure

\author{
--Manuscript Draft--
}

\begin{tabular}{|c|c|}
\hline \multicolumn{2}{|l|}{ Manuscript Number: } \\
\hline Article Type: & Method article \\
\hline Section/Category: & Crude oil toxicity \\
\hline Keywords: & $\begin{array}{l}\text { Oroboros Oxygraph; Mitochondrial Respiration; ROS Production; Proton Leak; } \\
\text { photo-modified PAH; Gill Filaments }\end{array}$ \\
\hline Corresponding Author: & $\begin{array}{l}\text { Dane Crossley II } \\
\text { University of North Texas } \\
\text { Denton, TX United States }\end{array}$ \\
\hline First Author: & Amanda Reynolds Kirby \\
\hline \multirow[t]{6}{*}{ Order of Authors: } & Amanda Reynolds Kirby \\
\hline & Gina L.J. Galli \\
\hline & Janna L Crossley \\
\hline & Lauren E. Sweet \\
\hline & Dane A. Crossley II \\
\hline & Aaron P. Roberts \\
\hline Abstract: & $\begin{array}{l}\text { Anthracene is a highly toxic polycyclic aromatic hydrocarbon (PAH), and its toxicity is } \\
\text { increased 8-fold after compounding exposure to UV radiation. Exposure to either the } \\
\text { parent or photo-modified compound has been shown to cause increases in reactive } \\
\text { oxygen species (ROS) production and lipid peroxidation. Since the majority of ROS } \\
\text { production occurs within mitochondria, we investigated simultaneous mitochondrial } \\
\text { respiration and ROS production in the gills of sheepshead minnows (Cyprinodon } \\
\text { variegatus) acutely (48h) exposed to anthraquinone }(40 \mu \mathrm{Hg} \text { l-1). Anthraquinone } \\
\text { exposure caused a } 25 \% \text { increase in oxidative phosphorylation with electrons donated } \\
\text { to Complex I (OXPHOSCI) and a } 33 \% \text { increase in Leak respiration with oligomycin } \\
\text { (Leak-OmyCI). ROS production was slightly increased (33.3\%) in Leak state with } \\
\text { oligomyocin respiring on Complex I substrates (Leak-OmyCI) after anthraquinone } \\
\text { exposure, but this value remained unchanged in all other respiratory states. When } \\
\text { ROS production was normalized to mitochondrial oxygen consumption, we found that } \\
\text { ROS production was decreased in all respiratory states, but most noticeably in the } \\
\text { Leak state. We speculate that differences in the antioxidant defense system may have } \\
\text { played a role in decreased ROS production. Overall, in this paper we present a novel } \\
\text { technique to measure mitochondrial function in the gill filaments of teleost fish exposed } \\
\text { to xenobiotic molecules, and we show anthraquinone exposure alters aspects of } \\
\text { oxidative phosphorylation and ROS production. }\end{array}$ \\
\hline \multirow[t]{4}{*}{ Suggested Reviewers: } & $\begin{array}{l}\text { Gigi Lau } \\
\text { OsloMet - storbyuniversitetet } \\
\text { gigi.lau@ibv.uio.no } \\
\text { Mitochondrial Researcher }\end{array}$ \\
\hline & $\begin{array}{l}\text { Georgina Cox } \\
\text { University of Guelph } \\
\text { cox@zoology.ubc.ca } \\
\text { Environmental Toxicology and Fish }\end{array}$ \\
\hline & $\begin{array}{l}\text { Rasphal Dhillon } \\
\text { The University of British Columbia } \\
\text { dhillon@zoology.ubc.ca } \\
\text { Mitochondrial Researcher }\end{array}$ \\
\hline & $\begin{array}{l}\text { Andrew Esbaugh } \\
\text { University of Texas at Austin }\end{array}$ \\
\hline
\end{tabular}




\begin{tabular}{|l|l|}
\hline $\begin{array}{l}\text { a.esbaugh@austin.utexas.edu } \\
\text { Previous mitochondrial work and environmental toxicology on fish }\end{array}$ \\
\hline $\begin{array}{ll}\text { Elena Fabbri } \\
\text { Universita di Bologna } \\
\text { elena.fabbri@unibo.it } \\
\text { Researcher in environmental toxicology }\end{array}$ \\
\hline $\begin{array}{l}\text { Kevin Brix } \\
\text { The University of British Columbia } \\
\text { kevinbrix@icloud.com } \\
\text { Environmental Toxicology }\end{array}$ \\
\hline Opposed Reviewers: & \\
\hline
\end{tabular}


Dear Dr Grosell,

Please find accompanying this letter our submission of the manuscript entitled: Gill Filament Permeabilization: A Novel Approach to Assess Mitochondrial Function in Sheepshead Minnows (Cyprinodon variegatus) following Anthraquinone Exposure for consideration for publication. In this manuscript we discuss our work in developing a novel technique to measure mitochondrial respiration in the gill filaments of a fish exposed to a single $\mathrm{PAH}$. We have made every effort to follow the formatting requirements of $\mathrm{CBP} C$.

Thank you for your consideration.

Dr Dane A Crossley II 
- Novel Gill Filament Preparation to Measure Mitochondrial Respiration and ROS Production

- Acute Anthraquinone Exposure Increased Respiration and ROS production in OXPHOS and Leak states

- Observed Results may be Evidence of Mounting Antioxidant Defense Response to Xenobiotic Molecues 
1

$7{ }^{1}$ Developmental and Integrative Biology Division, Department of Biological Sciences,

8 University of North Texas, Denton, Texas

$9 \quad{ }^{2}$ Faculty of Medical and Human Sciences, University of Manchester, Manchester, United

10 Kingdom

$11{ }^{3}$ Advanced Environmental Research Institute, Department of Biological Sciences, University of

12 North Texas, Denton, Texas

13

14 *Corresponding Author: Dane A. Crossley II; email: dane.crossley@unt.edu 


\section{Abstract}

Anthracene is a highly toxic polycyclic aromatic hydrocarbon (PAH), and its toxicity is

17 increased 8-fold after compounding exposure to UV radiation. Exposure to either the parent or

18 photo-modified compound has been shown to cause increases in reactive oxygen species (ROS)

19 production and lipid peroxidation. Since the majority of ROS production occurs within

20 mitochondria, we investigated simultaneous mitochondrial respiration and ROS production in the

21 gills of sheepshead minnows (Cyprinodon variegatus) acutely (48h) exposed to anthraquinone

$22\left(40 \mu \mathrm{g}^{-1}\right)$. Anthraquinone exposure caused a $25 \%$ increase in oxidative phosphorylation with

23 electrons donated to Complex I (OXPHOS $\mathrm{CI})$ and a $33 \%$ increase in Leak respiration with

24 oligomycin (Leak-OmycI). ROS production was slightly increased (33.3\%) in Leak state with

25 oligomyocin respiring on Complex I substrates (Leak-OmycI) after anthraquinone exposure, but

26 this value remained unchanged in all other respiratory states. When ROS production was

27 normalized to mitochondrial oxygen consumption, we found that ROS production was decreased

28 in all respiratory states, but most noticeably in the Leak state. We speculate that differences in

29 the antioxidant defense system may have played a role in decreased ROS production. Overall, in

this paper we present a novel technique to measure mitochondrial function in the gill filaments of

31 teleost fish exposed to xenobiotic molecules, and we show anthraquinone exposure alters aspects

32 of oxidative phosphorylation and ROS production.

34 Keywords: Oroboros Oxygraph; Mitochondrial Respiration; ROS Production; Proton Leak;

35 photo-modified PAH; Gill Filaments 


\section{Introduction}

Polycyclic aromatic hydrocarbons (PAHs) are a carcinogenic compound found in smoke, tar, and crude oil. PAHs are released into the atmosphere by the burning and distilling of coal ore

39 (Dipple, 1985), and into aquatic environments through the harvesting and transportation of crude oil (Pasparakis et al., 2019). Some PAHs contain photodynamic properties that are responsive to

41 wavelengths in the UVA spectrum $(315-400 \mathrm{~nm})$ and can magnify toxicity in aquatic systems,

42 resulting in photo-enhanced toxicity (Roberts et al., 2017). Photodynamic PAHs are excited by

43 UVA light $(380 \mathrm{~nm})$, resulting in the formation of excited singlet and triplet state molecules.

44 These molecules are highly reactive with their surrounding media and generate photo-modified

45 PAHs (byproducts), as well as reactive oxygen species (ROS), which enhances overall toxicity

46 leading to oxidative stress (Arfsten et al., 1996; Mallakin et al., 1999). The photo-modified

47 PAHs are typically oxidized, resulting in higher water solubility and bioavailability to aquatic

48 organisms than the parent PAHs. These molecules are highly reactive in tissues and attach to 49 membrane lipids, which compromise cellular and organelle membrane integrity (Sikkema et al., 50 1994).

Without the influence of $\mathrm{UV}$, anthracene is a highly toxic $\mathrm{PAH}$ with an $\mathrm{LC}_{50}$ of

52 approximately $16.6 \mu \mathrm{g} \mathrm{l}^{-1}$, which is enhanced eight-fold ( $\mathrm{LC}_{50}$ of $1.94 \mu \mathrm{g}^{-1}$ ) after co-UV

53 exposure (Weinstein and Polk, 2001). Bluegill sunfish (Lepomis macrochirus) exposed to $12 \mu \mathrm{g}$

$54 \mathrm{l}^{-1}$ of anthracene resulted in $100 \%$ mortality within nine hours of direct UV exposure (Bowling et

55 al., 1983). The photo modification of anthracene (as a result of co-UV exposure) forms over 20

56 toxic byproducts (including anthraquinone), and generally the photoproducts are more toxic than

57 the parent compounds (Mallakin et al., 1999). In the case of anthracene, $50 \%$ growth inhibition

58 in aquatic duckweed (Lemna gibba) was achieved at a concentration of $1.0 \mathrm{mg}^{-1}$, while the 
same growth inhibition was achieved in lower concentrations $\left(0.1 \mathrm{mg} \mathrm{l}^{-1}\right)$ (Huang et al., 1995).

60 Photodynamic PAHs (anthracene) absorb UV radiation resulting in an excited energy state and

61 oxidized photoproducts (anthraquinone). The energy released as the excited compound returns to

62 the ground state and can be transferred directly to cellular $\mathrm{O}_{2}$ or membrane lipids (Roberts et al.,

63 2017). This process of photosensitization has been proposed as the mechanism of toxicity (for

64 PAHs and their photoproducts) through the production of reactive oxygen species (ROS),

65 resulting in oxidative damage to tissues and membranes Mallakin et al., 1999; Roberts et al.,

66 2017; Weinstein and Polk, 2001). In fact, markers of oxidative stress (increased lipid

67 peroxidation and ROS production) were found in bluegill sunfish liver microsomes after 60

68 minutes of exposure to anthracene (3.015 $\left.\mathrm{g} \mathrm{ml}^{-1}\right)$ and UV light (Choi and Oris, 2000).

69 Considering that ROS production occurs in the mitochondrial complexes, we wanted to

70 measure the effects of anthraquinone on mitochondrial function (oxygen consumption and

71 coupling efficiency) while simultaneously measuring ROS production in sheepshead minnow gill

72 filaments. We chose the gill filament as a target tissue because PAHs easily flux across the gill

73 epithelium and are rapidly dispersed into the bloodstream (Ramachandran et al., 2006). In the

74 past, oxidative phosphorylation of the gills has been measured in purified isolated mitochondria.

75 However, this preparation requires large tissue samples, which is not possible in small fish

76 species, such as the sheepshead minnow. To this end, we have developed a novel, whole

77 permeabilized gill filament preparation to assess mitochondrial function and simultaneous ROS

78 production in sheepshead minnows (Cyprinodon variegatus) following acute $(48 \mathrm{~h})$

79 anthraquinone exposure. Permeabilization of the tissue removes the influence of the antioxidant

80 defense systems and cascade signaling and gives us access to the electron transport chain for

81 pharmacological manipulations (Pesta and Gnaiger, 2012). Here we show that the permeabilized 
82 gill preparation is suitable for mitochondrial measurements and can be successfully utilized for

83 toxicological investigations.

\section{Materials and Methods}

85 Animals

Adult, mix-sexed Sheepshead Minnows (Cyprinodon variegatus) were purchased from

87 Aquatic Biosystems (Fort Collins, CO) and overnighted to the University of North Texas. Upon arrival, minnows were housed in 1001 tanks filled with 25 ppt saltwater maintained at $26{ }^{\circ} \mathrm{C}$.

89 Saltwater was mixed in the lab by combining deionized facility water with Instant Ocean® Sea

90 Salt (United Pet Group, Blacksburg, VA). Minnows were kept on a 10:14 hour light:dark

91 photoperiod and fed Artemia sp. flake food ad libitum every other day, except $24 \mathrm{~h}$ prior to

92 experimentation. Water quality $(\mathrm{pH}[6.8-7.5]$, ammonia $[<5 \mathrm{ppm}]$, nitrite $[<1.0 \mathrm{ppm}]$, nitrate $[<$

$9340 \mathrm{ppm}])$ parameters were monitored daily.

94 Acute (48h) Anthraquinone Exposure

Adult minnows (two per replicate) were moved to 201 exposure tanks filled with $25 \mathrm{ppt}$ saltwater maintained at $26^{\circ} \mathrm{C}$. One tank contained anthraquinone $\left(40 \mu \mathrm{g}^{-1}\right)$ dissolved in DMSO,

97 and the other tank contained an equal volume of DMSO (dimethyl sulfoxide) to serve as a vehicle control. After $24 \mathrm{~h}$, minnows were transferred to new aquaria that were filled with $25 \mathrm{ppt}$ saltwater and a dose of either anthraquinone $\left(40 \mu \mathrm{g} \mathrm{l}^{-1}\right)$ or DMSO (equal volume). A $48 \mathrm{~h}$ static renewal exposure is a fairly standard procedure when assessing compound toxicity and is used as

101 a precaution of biodegradation and volatilization (Weinstein and Polk, 2001). The concentration

102 of anthraquinone used in this study is within environmentally relevant levels (less than $10 \mu \mathrm{g} \mathrm{ml}^{-}$

$103^{1}$ ) for anthracene and related byproducts. Temperature and oxygen saturation were monitored 104 throughout experimentation using a handheld YSI dissolved oxygen probe (YSI, Inc, Yellow 
105 Springs, $\mathrm{OH})$. Water parameters ( $\mathrm{pH}$, ammonia, nitrate, and nitrate) were monitored throughout 106 the exposure period. After $48 \mathrm{~h}$, the trial was terminated and minnows were euthanized using a 107 lethal dose of buffered MS-222 (100mg l-1 MS-222 and $\left.200 \mathrm{mg} \mathrm{l}^{-1} \mathrm{NaHCO}_{3}\right)$. Gill baskets were 108 removed from both sides of the fish and immediately processed according to the procedures 109 below.

Permeabilized Gill Filament Preparation

Gill arches were placed in ice-cold BIOPS (pH 7.1) containing [2.8 mM CaK 2 EGTA (pH

112 7.0), 7.2 mM K 2 EGTA (pH 7.0), $5.8 \mathrm{mM} \mathrm{Na} 2 \mathrm{ATP}, 6.6 \mathrm{mM} \mathrm{MgCl} \cdot 6 \mathrm{H}_{2} \mathrm{O}, 20 \mathrm{mM}$ Taurine, 15

$113 \mathrm{mM} \mathrm{Na} 2$ Phosphocreatine, $20 \mathrm{mM}$ Imidazole, $0.5 \mathrm{mM}$ Dithiothreitol, and $50 \mathrm{mM}$ 2-(N-

114 morpholino) ethanesulfonic acid] (Galli et al., 2016). Under a Lecia EZ4 dissecting scope (Lecia

115 Microsystems Inc., Buffalo Grove, IL) with a dark background, mucous and blood clots were

116 removed from the gill arches (figure 1). Gill arches were incubated at $4^{\circ} \mathrm{C}$ in BIOPS with

117 saponin $\left(50 \mu \mathrm{g} \mathrm{ml}^{-1}\right)$ on an orbital shaker (Cole-Parmer, Vernon Hills, IL) for 12 minutes at

118 speed two. Arches were triple washed (to remove excess lipids) for 10 minutes in $4^{\circ} \mathrm{C}$ MIR05

119 respiration medium ( $\mathrm{pH}$ 7.1) containing [0.5 mM EGTA, $3.0 \mathrm{mM} \mathrm{MgCl} 2 \cdot 6 \mathrm{H}_{2} \mathrm{O}, 60 \mathrm{mM} \mathrm{K}-2-(\mathrm{N}-$

120 morpholino) ethanesulfonic acid, $20 \mathrm{mM}$ Taurine, 10mM KH${ }_{2} \mathrm{PO}_{4}, 20 \mathrm{mM}$ HEPES, $110 \mathrm{mM}$ -

121 Sucrose, 1\% BSA] (Galli et al., 2016). Gill filaments were cut from the arches and wet weight

122 was recorded. Gill filaments (wet weight $2 \mathrm{mg}$ ) were added to each chamber of an Oroboros

123 Oxygraph 2K HR respirometer (Oroboros Instruments, Innsbruck, Austria) containing MIR05

124 respiration solution maintained at $30^{\circ} \mathrm{C}$. The chambers were hyper-oxygenated and oxygen

125 concentration was maintained between $200-400 \mathrm{~nm} \mathrm{ml}^{-1}$ during each trial. Mitochondrial

126 function analyses were conducted in two parts: 1) measurement of mitochondrial respiration with

127 simultaneous ROS production and 2) a cytochrome c test with measurement of OXPHOS $\mathrm{CIV}$. 
128 This was done because cytochrome $\mathrm{c}$ and TMPD with ascorbate (complex IV substrates) are

129 strong redox substances that consume $\mathrm{H}_{2} \mathrm{O}_{2}$ which interferes with the $\mathrm{H}_{2} \mathrm{O}_{2}$ calibration and

130 overall sensitivity of the method (Makrecka-Kuka et al., 2015).

131 The Oroboros was outfitted with O2K-fluorescence LED probes (Oroboros Instruments,

132 Innsbruck, Austria) to detect ROS flux within the Oxygraph chambers. The following protocol

133 measuring simultaneous ROS production and mitochondrial respiration is modified from

134 previously published studies (Krumschnabel et al., 2015; Suski et al., 2012). Amplex ${ }^{\mathrm{TM}}$ UltraRed

$135(10 \mu \mathrm{M})$, horseradish peroxidase $(1 \mathrm{U} / \mathrm{ml})$, and superoxide dismutase $(10 \mathrm{U} / \mathrm{ml})$ were injected

136 into each chamber to induce oxidation of Amplex ${ }^{\mathrm{TM}}$ UltraRed to red-fluorescent resorufin in the

137 presence of $\mathrm{H}_{2} \mathrm{O}_{2}$. The fluorescent signal was calibrated by stepwise injections of $400 \mu \mathrm{m} \mathrm{H}_{2} \mathrm{O}_{2}$

138 (final concentration; 0-2 mM).

139

Protocol 1: Respiratory states and ROS production

140 Respiratory substrates malate $(2 \mathrm{mM})$ and pyruvate $(5 \mathrm{mM})$ were injected into the

141 chambers and served as a measurement for LEAK respiration without adenylates while respiring

142 on Complex I substrates (LEAK-LNCI; table 1). Succinate (10 mM) was added to the chamber to

143 measure LEAK respiration with Complex I and II substrates without adenylates (LEAK-

$144 \mathrm{LN}_{\mathrm{CI}+\mathrm{CII}}$; table 1). OXPHOS $\mathrm{CI+CII}$ (table 1) was induced by adding saturating levels of ADP (5

$145 \mathrm{mM})$. Oligomycin $\left(2 \mu \mathrm{g} \mathrm{ml}^{-1}\right)$ was then added to the chambers to block the ATP synthase and

146 measure LEAK state with Oligomycin (LEAK-OmyCI+CI; table 1). Rotenone $(0.5 \mu \mathrm{M})$ was

147 titrated into the chambers to inhibit Complex I of the ETS and measure LEAK-OmyciI (table 1).

148 Lastly, Antimycin A $(2.5 \mu \mathrm{M})$ was added to the chambers to measure residual oxygen

149 consumption (ROX) or chamber respiration not attributed to mitochondrial respiration (table 1). 


\section{Protocol II: Cytochrome C test and OXPHOSC IV Respiration}

Malate $(2 \mathrm{mM})$, and pyruvate $(5 \mathrm{mM})$ were added to provide carriers for the citric acid cycle. Saturating concentrations of ADP $(5 \mathrm{mM})$ were injected into the chambers to initiate OXPHOS $_{\mathrm{CI}}$ and succinate $(10 \mathrm{mM})$ was added to provide substrates for complex II activation (OXPHOS $_{\mathrm{CI}+\mathrm{CII}}$; table 1). Cytochrome $\mathrm{c}(10 \mu \mathrm{M})$ was added to assess mitochondrial quality and to determine inner mitochondrial membrane integrity after permeabilized gill filament preparation (table 1). OXPHOS $\mathrm{CIV}$ was stimulated through tetramethyl-p-phenylene-diamine (TMPD; 0.5mM) and ascorbate (2 mM) injections (table 1).

\section{Calculations and Statistical Analysis}

Trials were excluded from the data analysis when respiration rate increased above $15 \%$ after cytochrome $\mathrm{c}$ injection and when respiratory control ratios (RCR) were lower than 6, which indicated a damaged preparation (Brand, 2011). All fluxes were corrected for background $\mathrm{O}_{2}$ consumption by subtracting the respiration rate after gills were added but before mitochondrial substrates and inhibitors were added. Respiration rate and ROS production were normalized to

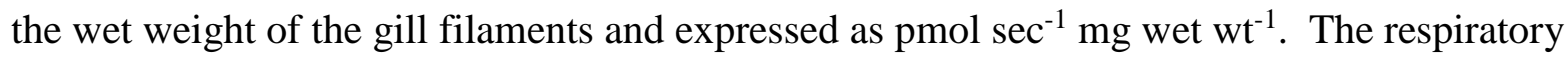
control ratio $(\mathrm{RCR})$ was calculated by dividing $\mathrm{OXPHOS}_{\mathrm{CI}+\mathrm{CII}}$ respiration rate by $\mathrm{LEAK}_{\mathrm{LNCI}+\mathrm{CII}}$ in protocol I. All statistical tests were performed using Statistica Version 13.3. A repeatedmeasures ANOVA with a Tukey HSD test was used to make comparisons in mitochondrial respiration and ROS production between treatments. A student's t-test was used to check for difference at OXPHOS $\mathrm{CIV}$ and RCRs between control and exposed minnows.

\section{Results and Discussion}

To date, the effects of individual PAH exposure on intact mitochondrial function are relatively unknown. Few studies have highlighted the effects of crude oil exposure on 
174 mitochondrial function, which provided the framework for our investigation. We have developed

175 a new preparation for measuring mitochondrial function in whole gill preparations from small

176 fish. Furthermore, we have shown exposure to anthraquinone effects aspects of mitochondrial

177 electron transport chain function and ROS production.

178

179

180

181

182

183

184

185

186

187

188

189

190

191

192

193

194

195

196

\section{Development of a permeabilized whole-gill mitochondrial preparation}

Permeabilized mitochondrial preparations allow detailed characterization of electron transport chain function in their normal intracellular position, thus preserving essential

interactions with the cytoskeleton and other organelles. We adapted protocols for skeletal muscle preparations to develop a permeabilized whole-gill preparation (Fig. 1A). Our RCR values

(control: $3.88 \pm 0.49$ and exposed: $4.42 \pm 0.42$ ) from permeabilized gill filaments are consistent with published values in teleost cardiac and skeletal muscle (Fig. 1B; Chung et al., 2017;

Guderley and Johnston, 1996; Iftikar and Hickey, 2013). Furthermore, there were negligible effects of Cytochrome $\mathrm{C}$, which suggests the inner mitochondrial membrane was intact. Taken together, these results suggest the fibers were of excellent quality with no overt signs of dysfunction from the permeabilization process (Brand, 2011). Therefore, we consider this preparation is appropriate for studying mitochondrial function in whole-gills, which is particularly useful for studies in small fish.

\section{Effects of anthraquinone on Electron Transport Chain Function and ROS production}

There was a tendency for anthraquinone exposure to cause an increase in oxygen consumption across all respiratory states. This effect was particularly pronounced, and statistically significant, when Complex I and II substrates were combined in both the OXPHOS and Leak-Omy states (Fig. 1B). The fact that both Leak and OXPHOS increased with anthraquinone exposure meant that RCR's ratios were similar between exposed minnows and 
controls ( $3.88 \pm 0.49$ and $4.42 \pm 0.44$ respectively), suggesting that mitochondrial efficiency remained unchanged. These results suggest anthraquinone exposure increases mitochondrial oxidative capacity in minnows. Given that ATP demand is increased during toxic exposure (e.g., recruitment of ATP-dependent ion channels), a greater mitochondrial capacity may represent a compensatory mechanism to match ATP supply to demand during environmental stress.

Anthraquinone exposure led to a $30 \%$ increase in ROS production during Leak-Omy $\mathrm{CI}_{+} \mathrm{CII}$ respiratory state (Fig. 1D). However, a different pattern emerged when ROS production was normalized to mitochondrial oxygen consumption. For all leak respiratory states (Leak-LnCI, Leak-OmycI+CI, Leak-OmycII), ROS production was reduced by 20 to $40 \%$ in mitochondria from minnows exposed to anthraquinone (Fig 1E). Therefore, after differences in oxygen consumption are taken into account, our results suggest ROS production is lower in minnows exposed to anthraquinone, compared to controls. While we did not address the mechanism underlying the differences in ROS production, it is possible that minnows exposed to anthraquinone may mount a protective response by actively suppressing pathways involved in ROS production, or upregulating the antioxidant defense system (Regoli et al., 2011). Support for the latter hypothesis comes from studies in liver mitochondria of goldfish (Carassius auratus), which showed levels of superoxide dismutase and catalase were elevated in exposed to phenanthrene exposure (a PAH that is abundant in aquatic systems) (Yin et al., 2007). Nevertheless, it is possible that the exposure length or concentration was not long or high enough to overwhelmed the antioxidant defense system, leading to an increase in ROS production, similar to previous studies (Yin et al., 2007). Further research is necessary to resolve these speculations, which could include measurements of antioxidants and markers of oxidative damage (lipid peroxidation). 
In contrast to our study, Xu and colleagues (2017) found that larval red drum (Sciaenops

221 ocellatus) exposed to crude oil concentrations of $4.8 \mu \mathrm{g}^{-1} \Sigma \mathrm{PAH} 50$ at 24,h, 48h, and $72 \mathrm{~h}$ had

222 differential transcription profiles that were consistent with changes in mitochondrial function,

223 mitochondrial transmembrane potential, oxidative stress response pathways, and cell death

224 signaling (Xu et al., 2017). In adult red drum, mitochondrial function and performance was

225 assessed following $24 \mathrm{~h}$ exposure at concentrations of $29.6 \pm 7.4 \mu \mathrm{g} \mathrm{l}^{-1}$ and $64.5 \pm 8.9 \mu \mathrm{g} \mathrm{l}^{-1}$

$226 \Sigma \mathrm{PAH}_{50}$ and they found no change in Leak respiration, maximal ETS, or coupling controls ratios

227 (markers of mitochondrial dysfunction) after 24h of crude oil exposure (Johansen and Esbaugh,

228 2019). Mitochondrial function has also been measured in adult Mahi-mahi (Coryphaena

229 hippurus) that were exposed to crude oil $\left(9.6 \pm 1.7 \mu \mathrm{g} \mathrm{l}^{-1} \Sigma \mathrm{PAH}_{50}\right)$ for $24 \mathrm{~h}$ and the authors

230 determined that while OXPHOS CI $_{\text {and }}$ OXPHOS $_{\mathrm{CII}}$ respiration was decreased, classic markers of

231 mitochondrial dysfunction were not observed (no change in leak respiration, maximal ETS, or

232 coupling control ratios) (Kirby et al., 2019). It should be mentioned that the crude oil

233 concentrations used in the $24 \mathrm{~h}$ exposures are environmentally relevant to concentrations that

234 occurred during the Deepwater Horizon Oil Spill (Wade et al., 2011) and the lowest doses were

235 previously shown to affect swim performance and aerobic scope in adult fish (Johansen and

236 Esbaugh, 2017; Mager et al., 2014). Taken together, these studies and ours suggest the effects of

237 crude oil and their constituents on fish mitochondrial function are variable and unpredictable.

238 Clearly, more research needs to be conducted in other areas of mitochondrial bioenergetics to

239 determine the mechanisms of toxicity that crude oil and individual PAH have on teleost

240 mitochondrial function. 


\section{Acknowledgments}

244 This research was made possible by a grant from The Gulf of Mexico Research Initiative. Data

245 are publicly available through the Gulf of Mexico Research Initiative Information \& Data

246 Cooperative (GRIIDC) at https://data.gulfresearchinitiative.org (doi: 10.7266/N71Z4304). 
Tables and Figure Legends

249 Table 1: The action and subsequent mitochondrial states as a result of substrates and inhibitors

250 used in Protocol I and II.

\begin{tabular}{|c|c|c|c|c|}
\hline & Action & State & Electron Entry & Abbreviation \\
\hline \multicolumn{5}{|l|}{ PROTOCOL I } \\
\hline $\begin{array}{l}\text { Malate }(2 \mathrm{mM}) \\
\text { pyruvate }(5 \mathrm{mM})\end{array}$ & $\begin{array}{l}\text { Citric acid cycle and } \\
\text { glycolysis } \\
\text { intermediates. Substrates } \\
\text { for Complex I-linked } \\
\text { respiration }\end{array}$ & $\begin{array}{l}\text { LEAK respiration } \\
\text { without adenylates } \\
(\mathrm{LN})\end{array}$ & Complex I & LEAK-LN $_{\mathrm{CI}}$ \\
\hline Succinate $(10 \mathrm{mM})$ & $\begin{array}{l}\text { Citric acid cycle } \\
\text { intermediate. Substrate } \\
\text { for Complex II-linked } \\
\text { respiration }\end{array}$ & $\begin{array}{l}\text { LEAK respiration } \\
\text { without adenylates } \\
\text { (LN) }\end{array}$ & $\begin{array}{l}\text { Complex I \& II } \\
\text { (convergent } \\
\text { electron entries } \\
\text { into the Q- } \\
\text { junction) }\end{array}$ & LEAK-LN $_{\mathrm{CI}+\mathrm{CII}}$ \\
\hline $\begin{array}{l}\text { Saturating ADP } \\
(5 \mathrm{mM})\end{array}$ & $\begin{array}{l}\text { Substrate for ATP } \\
\text { synthase }\end{array}$ & $\begin{array}{l}\text { OXPHOS } \\
\text { respiration }\end{array}$ & Complex I \& II & OXPHOS $_{\mathrm{CI}}$ \\
\hline $\begin{array}{l}\text { Oligomycin }(2 \mu \mathrm{g} \\
\left.\mathrm{ml}^{-1}\right)\end{array}$ & $\begin{array}{l}\text { Inhibitor of the } \\
\mathrm{F}_{1} \mathrm{~F}_{0} \text { ATPase (Complex } \\
\mathrm{V} \text { ) }\end{array}$ & $\begin{array}{l}\text { LEAK state } \\
\text { induced with } \\
\text { oligomycin }\end{array}$ & Complex I \& II & $\overline{\text { LEAK-Omy }_{\mathrm{CI}+\mathrm{CII}}}$ \\
\hline Rotenone $(0.5 \mu \mathrm{M})$ & Inhibitor of Complex I & $\begin{array}{l}\text { LEAK state } \\
\text { induced with } \\
\text { oligomycin }\end{array}$ & Complex II & LEAK-Omy $_{\text {CII }}$ \\
\hline $\begin{array}{l}\text { Antimycin A (2.5 } \\
\mu \mathrm{M})\end{array}$ & Inhibitor of Complex III & $\begin{array}{l}\text { Residual oxygen } \\
\text { consumption }\end{array}$ & N/A & ROX \\
\hline $\begin{array}{l}\text { Respiratory } \\
\text { Control Ratio }\end{array}$ & $\begin{array}{l}\text { Indicates the degree of } \\
\text { coupling OXHPOS and } \\
\text { ATP synthase }\end{array}$ & $\begin{array}{l}\text { OXPHOS }_{\mathrm{CI}-\mathrm{CIV}} / \\
\text { Leak-LN }_{\mathrm{CI}+\mathrm{CII}}\end{array}$ & N/A & RCR \\
\hline \multicolumn{5}{|l|}{ PROTOCOL II } \\
\hline $\begin{array}{l}\text { Malate }(2 \mathrm{mM}) \\
\text { pyruvate }(5 \mathrm{mM})\end{array}$ & $\begin{array}{l}\text { Citric acid cycle and } \\
\text { glycolysis intermediates, } \\
\text { respectively. Substrates } \\
\text { for Complex I-linked } \\
\text { respiration }\end{array}$ & $\begin{array}{l}\text { LEAK respiration } \\
\text { without adenylates } \\
\text { (LN) }\end{array}$ & Complex I & LEAK-LN $_{\mathrm{CI}}$ \\
\hline $\operatorname{ADP}(5 \mathrm{mM})$ & $\begin{array}{l}\text { Substrate for ATP } \\
\text { synthase }\end{array}$ & $\begin{array}{l}\text { OXPHOS } \\
\text { respiration }\end{array}$ & Complex I \& II & OXPHOS $_{\mathrm{CI}}$ \\
\hline Succinate $(10 \mathrm{mM})$ & $\begin{array}{l}\text { Citric acid cycle } \\
\text { intermediate. Substrate } \\
\text { for Complex II-linked } \\
\text { respiration }\end{array}$ & $\begin{array}{l}\text { LEAK respiration } \\
\text { without adenylates } \\
\text { (LN) }\end{array}$ & Complex I \& II & $\mathrm{OXPHOS}_{\mathrm{CI}+\mathrm{CII}}$ \\
\hline $\begin{array}{l}\text { Cytochrome C (10 } \\
\mu \mathrm{M})\end{array}$ & $\begin{array}{l}\text { Component of the } \\
\text { electron transport chain }\end{array}$ & N/A & N/A & N/A \\
\hline Ascorbate $(2 \mathrm{mM})$ & $\begin{array}{l}\text { Antioxidant to prevent } \\
\text { autoxidation of TMPD } \\
\text { (see next step) }\end{array}$ & N/A & N/A & N/A \\
\hline $\begin{array}{l}\text { Tetramethyl-p- } \\
\text { phenylene-diamine } \\
\text { (TMPD; } 0.5 \mathrm{mM} \text { ) }\end{array}$ & $\begin{array}{l}\text { Electron donor to } \\
\text { Complex IV }\end{array}$ & $\begin{array}{l}\text { OXPHOS } \\
\text { respiration }\end{array}$ & Complex IV & OXPHOS $_{\mathrm{CIV}}$ \\
\hline
\end{tabular}


Figure 1: Gill arches (A) extracted from a Sheepshead Minnow (Cyprinodon variegatus) and viewed under a Lecia EZ4 dissecting scope prior to permeabilization. Protocol one measurements of mitochondrial respiration (B) and simultaneous ROS production (D) after $48 \mathrm{~h}$ of exposure in control tanks (open bars) or in anthraquinone $\left(40 \mu \mathrm{g}^{-1}\right)$ dosed tanks (closed bars). Measurements from protocol two on OXPHOS respiration (C). ROS production normalized for mitochondrial respiration rate (E). Data are represented as means \pm s.e. Single asterisk denotes significant differences between treatments $(\mathrm{p}<0.05)$.

\section{References}

1. Arfsten, D. P., Schaeffer, D. J., \& Mulveny, D. C. (1996). The Effects of Near Ultraviolet Radiation on the Toxic Effects of Polycyclic Aromatic Hydrocarbons in Animals and Plants: A Review. Ecotoxicology and Environmental Safety, 33(1), 1-24. doi:http://dx.doi.org/10.1006/eesa.1996.0001

2. Brand, M.D. and Nicholls, D. G., 2011. Assessing mitochondrial dysfunction in cells. Biochemical Journal, 435(Pt 2), 297-312. doi:10.1042/BJ20110162

3. Bowling, J., Leversee, G., Landrum, P., \& Giesy, J. (1983). Acute mortality of anthracene-contaminated fish exposed to sunlight. Aquatic Toxicology, 3(1), 79-90.

4. Choi, J., and Oris, J. T., 2000. Evidence of oxidative stress in bluegill sunfish (Lepomis macrochirus) liver microsomes simultaneously exposed to solar ultraviolet radiation and anthracene. Environmental Toxicology and Chemistry, 19(7), 1795-1799. doi:10.1002/etc.5620190713

5. Chung, D.J., Bryant, H.J., Schulte, P.M., 2017. Thermal acclimation and subspeciesspecific effects on heart and brain mitochondrial performance in a eurythermal teleost ( $<\mathrm{em}>$ Fundulus heteroclitus $</ \mathrm{em}>$ ). The Journal of Experimental Biology 220, 14591471.

6. Dipple, A.1985). Polycyclic Aromatic Hydrocarbon Carcinogenesis. 283, 1-17. doi:10.1021/bk-1985-0283.ch001

7. Galli, G.L.J., Crossley, J., Elsey, R.M., Dzialowski, E.M., Shiels, H.A., Crossley, D.A., 2016. Developmental plasticity of mitochondrial function in American alligators, $<\mathrm{em}>$ Alligator mississippiensis $</ \mathrm{em}>$. American Journal of Physiology - Regulatory, Integrative and Comparative Physiology 311, R1164-R1172.

8. Guderley, H., Johnston, I., 1996. Plasticity of fish muscle mitochondria with thermal acclimation. Journal of Experimental Biology 199, 1311-1317.

9. Huang, X.D., Dixon, D.G., Greenberg, B.M., 1995. Increased Polycyclic Aromatic Hydrocarbon Toxicity Following Their Photomodification in Natural Sunlight: Impacts on the Duckweed Lemna gibba L. G-3. Ecotoxicology and Environmental Safety 32, 194-200. 
10. Iftikar, F.I., Hickey, A.J.R., 2013. Do Mitochondria Limit Hot Fish Hearts? Understanding the Role of Mitochondrial Function with Heat Stress in Notolabrus celidotus. PLOS ONE 8, e64120.

11. Johansen, J.L., Esbaugh, A.J., 2017. Sustained impairment of respiratory function and swim performance following acute oil exposure in a coastal marine fish. Aquatic Toxicology 187, 82-89.

12. Johansen, J.L., Esbaugh, A.J., 2019. Oil-induced responses of cardiac and red muscle mitochondria in red drum (Sciaenops ocellatus). Comparative Biochemistry and Physiology Part C: Toxicology \& Pharmacology 219, 35-41.

13. Kirby, A.R., Cox, G.K., Nelson, D., Heuer, R.M., Stieglitz, J.D., Benetti, D.D., Grosell, M., Crossley, D.A., 2019. Acute crude oil exposure alters mitochondrial function and ADP affinity in cardiac muscle fibers of young adult Mahi-mahi (Coryphaena hippurus). Comparative Biochemistry and Physiology Part C: Toxicology \& Pharmacology 218, 8895.

14. Krumschnabel, G., Fontana-Ayoub, M., Sumbalova, Z., Heidler, J., Gauper, K., Fasching, M., \& Gnaiger, E. (2015). Simultaneous high-resolution measurement of mitochondrial respiration and hydrogen peroxide production. Methods Mol Biol, 1264, 245-261. doi:10.1007/978-1-4939-2257-4_22

15. Mager, E.M., Esbaugh, A.J., Stieglitz, J.D., Hoenig, R., Bodinier, C., Incardona, J.P., Scholz, N.L., Benetti, D.D., Grosell, M., 2014. Acute embryonic or juvenile exposure to Deepwater Horizon crude oil impairs the swimming performance of mahi-mahi (Coryphaena hippurus). Environ Sci Technol 48, 7053-7061.

16. Mallakin, A., McConkey, B.J., Miao, G., McKibben, B., Snieckus, V., Dixon, D.G., Greenberg, B.M., 1999. Impacts of structural photomodification on the toxicity of environmental contaminants: anthracene photooxidation products. Ecotoxicology and Environmental Safety 43, 204-212.

17. Makrecka-Kuka, M., Krumschnabel, G., and Gnaiger, E., 2015. High-Resolution Respirometry for Simultaneous Measurement of Oxygen and Hydrogen Peroxide Fluxes in Permeabilized Cells, Tissue Homogenate and Isolated Mitochondria. Biomolecules, 5(3), 1319-1338. doi:10.3390/biom5031319

18. Pasparakis, C., Esbaugh, A. J., Burggren, W., \& Grosell, M., 2019. Impacts of deepwater horizon oil on fish. Comparative Biochemistry and Physiology Part C: Toxicology \& Pharmacology, 224, 108558. doi:https://doi.org/10.1016/j.cbpc.2019.06.002

19. Pesta, D. and Gnaiger, E., 2012. High-Resolution Respirometry: OXPHOS Protocols for Human Cells and Permeabilized Fibers from Small Biopsies of Human Muscle \# $T$ Mitochondrial Bioenergetics (Vol. 810, pp. 25-58).

20. Ramachandran, S.D., Sweezey, M.J., Hodson, P.V., Boudreau, M., Courtenay, S.C., Lee, K., King, T., Dixon, J.A., 2006. Influence of salinity and fish species on PAH uptake from dispersed crude oil. Marine pollution bulletin 52, 1182-1189.

21. Regoli, F., Giuliani, M.E., Benedetti, M., Arukwe, A., 2011. Molecular and biochemical biomarkers in environmental monitoring: A comparison of biotransformation and antioxidant defense systems in multiple tissues. Aquatic Toxicology 105, 56-66.

22. Roberts, A.P., Alloy, M.M., Oris, J.T., 2017. Review of the photo-induced toxicity of environmental contaminants. Comparative Biochemistry and Physiology Part C: Toxicology \& Pharmacology 191, 160-167. 
23. Sikkema, J., de Bont, J. A., \& Poolman, B., 1994. Interactions of cyclic hydrocarbons with biological membranes. Journal of Biological Chemistry, 269(11), 8022-8028.

24. Suski, J. M., Lebiedzinska, M., Bonora, M., Pinton, P., Duszynski, J., and Wieckowski, M. R., 2012. Relation between mitochondrial membrane potential and ROS formation. Methods Mol Biol, 810, 183-205. doi:10.1007/978-1-61779-382-0_12

25. Wade, T.L., Sweet, S.T., Sericano, J.L., Guinasso, N.L., Diercks, A.R.R., Highsmith, R.C., Asper, V.L., Joung, D.D., Shiller, A.M., Lohrenz, S.E., 2011. Analyses of water samples from the Deepwater Horizon oil spill: Documentation of the subsurface plume. Monitoring and Modeling the deepwater horizon oil spill: a record-breaking enterprise, 77-82.

26. Weinstein, J.E., Polk, K.D., 2001. Phototoxicity of anthracene and pyrene to glochidia of the freshwater mussel Utterbackia imbecillis. Environmental Toxicology and Chemistry 20, 2021-2028.

27. Xu, E.G., Khursigara, A.J., Magnuson, J., Hazard, E.S., Hardiman, G., Esbaugh, A.J., Roberts, A.P., Schlenk, D., 2017. Larval Red Drum (Sciaenops ocellatus) Sublethal Exposure to Weathered Deepwater Horizon Crude Oil: Developmental and Transcriptomic Consequences. Environmental Science \& Technology 51, 10162-10172.

28. Yin, Y., Jia, H., Sun, Y., Yu, H., Wang, X., Wu, J., Xue, Y., 2007. Bioaccumulation and ROS generation in liver of Carassius auratus, exposed to phenanthrene. Comparative Biochemistry and Physiology Part C: Toxicology \& Pharmacology 145, 288-293. 

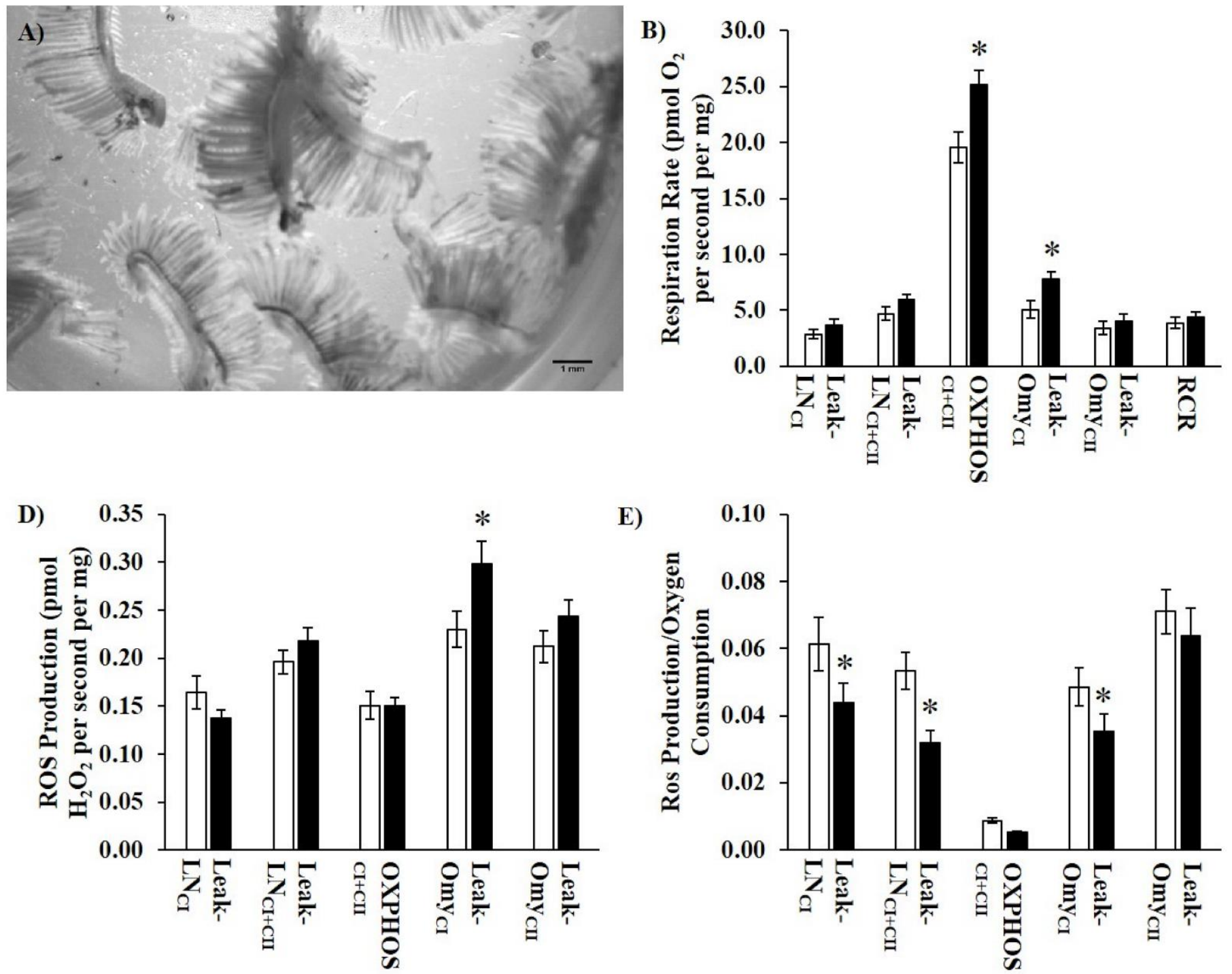
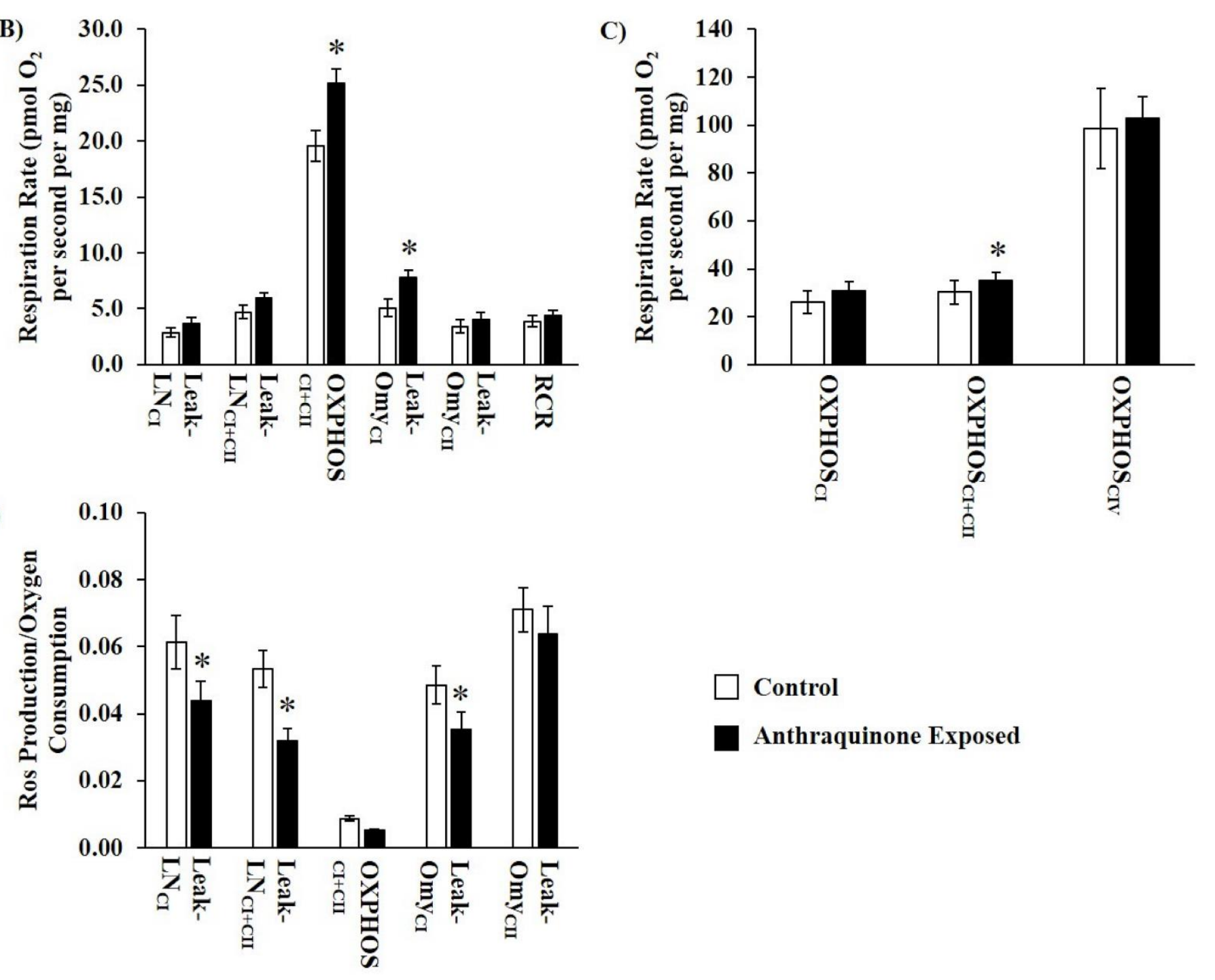

$\square$ Control

anthraquinone Exposed 
Conflict of Interest

\section{Disclosures}

No conflicts of interest, financial or otherwise, are declared by the author(s). 